\title{
Forscher und Entdecker
}

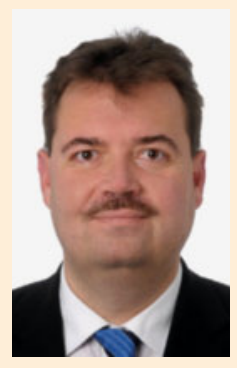

Liebe Kolleginnen und Kollegen,

der Mensch ist ein Reisender, ein Forscher und ein Entdecker. Er lebt und arbeitet in den extremsten Umgebungen, die der Planet Erde zu bieten hat - und darüber hinaus. In der vorliegenden Ausgabe der FTR lesen Sie über den Schutz des menschlichen Körpers vor hohen G-Kräften, über die medizinischen Herausforderungen des Trekkings und Bergsteigens an den höchsten Gipfeln Afrikas sowie über die Erfahrungen eines Schiffsarztes auf Expeditionsreisen. Sie lesen aber auch über Herausforderungen außerhalb der Erde - über die medizinischen Aspekte der Atmosphären auf zukünftigen bemannten Mond- und Marsmissionen.

Seit 44 Jahren hat kein Mensch mehr einen anderen Himmelskörper betreten. Dafür haben wir uns in der Zwischenzeit daran gewöhnt, es uns mit den technischen Errungenschaften der Raumfahrt im Alltag bequem zu machen. Würde jemand die Abschaltung der Satellitensysteme fordern, ein Leben ohne Handy, ohne TV, ohne Wetterprognosen, ohne Navigation und ohne Internet - der Aufschrei wäre enorm. Aber geht es um Forschung und bemannte Raumfahrt, wird der Horizont plötzlich ganz klein.

Bereits als die ISS überhaupt noch gar nicht vollständig in Betrieb war und die meisten wissenschaftlichen Experimente noch in der Vorbereitung steckten, haben bereits Politiker und Medienvertreter über kümmerliche wissenschaftliche Ergebnisse gemeckert. Man schien nicht einmal diese Ergebnisse überhaupt erst abwarten zu wollen. Bis heute werden auf der ISS unzählige wissenschaftliche Erkenntnisse produziert, von denen bei einigen bereits nach kurzer Zeit verstanden wurde, dass sie bahnbrechend sind. Wiederum andere Ergebnisse aus der Forschung im All werden deutlich länger brauchen, bis ihre Bedeutung erkannt ist. Denn der Zeithorizont der Wissenschaft ist zum Glück deutlich länger als die des durchschnittlichen menschlichen Geistes, wenn er sich abmüht, die Zukunft vorherzusagen.

Es gibt Menschen, die behaupten - in unterschiedlichen, mehr oder weniger klugen Variationen -, dass erst alle Dinge auf der Erde in Ordnung gebracht werden müssten, bevor sich der Blick ins All richten dürfte. Die belebte Erdatmosphäre endet nach spätestens $10 \mathrm{~km}$ in vertikaler Richtung. Der Verstand einiger Menschen anscheinend auch. Wie gefangen durch eine unsichtbare geistige Mauer verweigern manche mit aller Konsequenz den Blick darüber hinaus.

Aber die Welt wird nicht vorangebracht durch Menschen, die eingrenzen und ignorieren. Unsere Welt wurde immer schon vorangebracht durch die Visionäre, die Neugierigen und die Mutigen. Menschen werden durch große Ziele geeint, aber nie durch Kleingeist. Ein Stopp der bemannten Raumfahrt und Exploration würde kein einziges fundamentales Problem auf unserer Erde lösen. Aber sie würde die Menschheit einer ihrer größten Chancen berauben.

Wenn eines Tages der erste Mensch seinen Fuß auf den roten, staubigen Boden des Planten Mars setzen wird, nach mühsamer und langer Reise, werden Milliarden Menschen auf der Erde zusehen. Unter der hauchdünnen Atmosphäre des blauen und verletzlichen Planten Erde werden sie zusehen, wie einer ihrer Spezies die ersten vorsichtigen Schritte auf unserem Nachbarplaneten macht. Die Gefühle, Visionen und Träume von Milliarden Menschen werden dabei sein. Herkunft, Religion, Hautfarbe und kleinliche Konflikte: unbedeutend. Weil wir das tun, wofür unsere Spezies gemacht ist: zu forschen und zu entdecken.

Ihr

Prof. Dr. Dr. Oliver Ullrich 